\title{
SEJARAH DAN TIPOLOGI TAREKAT DALAM PANDANGAN TASAWUF DAN MAKRIFAT
}

\author{
Miftakhur Ridlo \\ Institut Agama Islam Uluwiyah Mojokerto \\ rheydlo@yahoo.co.id
}

\begin{abstract}
Tariqa is a fascinating historical phenomenon to study. Because of important events in history, the contribution of the Tariqa apparently is not small, like the Sanusiyyah order in Libya, which was instrumental in driving out the Italian invaders under the leadership of Umar Mukhtar. This paper will examine the history and typology of the Tariqa and its Tariqa components.
\end{abstract}

Keyword: Tariqa, Sufism, Ma'rifat.

Tarekat adalah salah satu fenomena sejarah yang menarik
untuk di kaji. Karena dalam peristiwa-peristiwa penting
dalam sejarah, andil tarekat rupanya tidak kecil.Seperti
tarekat Sanusiyyah di Libya yang berjasa mengusir penjajah
Italia di bawah pimpinan Umar Mukhtar.Tulisan ini akan
mengkaji sejarah dan tipoligo tarekat beserta komponen-
komponen tarekat.
Keyword:Tarekat, Tasawuf,Ma'rifat.




\section{Pendahuluan}

Tarekat merupakan kepanjangan tangan dari tasawuf yang ketika awal kemunculanya hanya di praktekkan secara individu. Baru setelah pada abad keempat tasawuf mulai menggeliat dan di praktekkan secara kolektif serta beranggotakan orang-orang awam yang kemudian berubah nama menjadi tarekat.Tarekat mempunyai peran yang cukup signifikan dalam mewarnai sejarah peradaban Islam. John Obert Voll menyatakan, ada tiga komunitas yang selalu terlibat dalam proses kontinuitas dan perubahan perdaban Islam, setelah runtuhnya kekuatan politik Islam yaitu ulama fiqih, para pedagang muslim, dan asosiasi sufi (tarekat) ${ }^{1}$. Tulisan berikut akan membahas secara global seluk-beluk tarekat dan pernak-perniknya.

\section{Pengertian Tarekat}

Secara etimologis tarekat berasal dari bahasa arab,tariqah, yang berarti jalan kecil ${ }^{2}$, cara, metode, madzhab, aliran dan haluan ${ }^{3}$.Amin Al-kurdy mengemukakan tiga macam definisi tarikat secara terminologis :

1- Tariqah adalah mengamalkan shari'at dan menghayati inti shari'at itu, serta menjauhkan hal-hal yang bisa melalaikan pelaksanaan semua inti dan tujuan shari'at itu.

2- Tariqah adalah melaksanan semua perintah shari'at dan menjauhi semua laranganya dengan sekuat tenaga lahir dan batin.

3- Tariqah adalah menjauhi hal-hal yang haram,makruh, dan berlebihan dalam hal yang mubah serta melaksanakan hal-hal yang wajib dan

${ }^{1}$ M.Muhsin Jamil, Tarekat dan Dinamika Sosial Politik: Tafsir sosial Sufisme Nusantara(Yogyakarta: Pustaka pelajar,2005),35.

2 Supriana dan M.karman. Materi pendidikan Agama Islam.(Bandung: Rosda,2004)255.

3 Muhyiddin Abdusshomad. Hujjah NU Akidah-Amaliah-Tradisi.( Surabaya: Khalista,2008)103. 
sunnah dengan sekuat tenaga di bawah bimbingan seorang guru yang sudah mencapai level marifat. ${ }^{4}$

Menurut L.Massignon, yang pernah melakukan penelitian terhadap kehidupan tasawuf di beberapa negara islam, menarik suatu kesimpulan bahwa istilah tarikat mempunya dua macam pengertian :

1- Tarikat yang di artikan sebagai pendidikan kerohanian yang sering dilakukan oleh orang-orang yang menempuh kehidupan tasawuf. Pengertian ini menonjol pada abad ke-9 sampai ke-11 Masehi.

2- Tarekat yang di artikan sebagai perkumpulan yang di asuh oleh seorang guru murshid (pembimbing) ${ }^{5}$. Dalam perkembanganya, tarekat menjadi organisasi keagamaan kaum sufi dengan jumlah yang banyak dan nama yang berbeda-beda. Tarekat ini tersebar ke Asia tenggara dan tengah, Afrika timur dan utara, India, Iran dan Turki. ${ }^{6}$

Dari penjelasan di atas, penulis berkesimpulan bahwa tarekat secara umum adalah subuah upaya pendekatan diri kepada allah dengan jalan mengamalkan shari'at yang terkodifikasi dalam Al-qur'an dan sunnah. Dengan demikian, maka ber-tarikat tidak melulu harus melalui prosedur bai'at kepada seorang murshid dan harus mengikuti ritual-ritual husus yang berafiliasi kepada sebuah kelompok tarikat tertentu, tapi banyak sekali jalan menuju tuhan sebanyak tarikan nafas anak $\mathrm{Adam}^{7}$. Seperti yang di gambarkan oleh Sayyid bakri dalam kifayatul atqiya' bahwa setiap orang mempunyai cara-cara tersendiri untuk sampai kepada allah, ada yang memilih menjadi pendidik sebagai jalan taqarrub-nya kepada allah, ada

${ }^{4}$ Amin Al-kurdy. Tanwir Al-qulub Fi mu'amalati Allam Al-guyub.( Surabaya: Alhidayah), 407 .

${ }^{5}$ A.Mustofa. Akhlak Tasawuf.( Bandung: Pustaka Setia.1999),281.

${ }^{6}$ Supriana dan M.karman. Materi pendidikan Agama Islam.(Bandung: Rosda,2004), 256.

${ }^{7}$ Abdul Halim Mahmud,Al-mundid min Al-dalal: Dirasat Wa abhas An Tasawuf (Misr : Dar Al-kutub Al-misriyah),196. 
yang membaca aurad, dan ada juga yang menjadi pelayan masyarakat. ${ }^{8}$ Karena tarekat adalah ibarat lautan yang sangat luas, shari'at adalah kapalnya, dan hakikat adalah ibarat mutiara. Maka untuk sampai kepada Allah seseorang harus berjalan sesuai dengan shari'at (petunjuk). Seperti seorang yang berburu mutiara, dia tidak akan mungkin mampu mendapatkan mutiara jika tidak mengarungi lautan (tarikat), dan dia akan tenggelam jika mengarungi lautan tanpa kapal (shari'at) ${ }^{9}$. Dalam perkembangan selanjutnya, makna tarekat menyempit menjadi sebuah organisasi keagaman yang terstruktur dan di pimpin oleh seorang murshid.

Shari'at, tarekat, dan hakikat harus selalu sejalan. Karena ketiga hal itu merupakan manifestasi dari islam, iman, dan ihsan. Hakikat tanpa Shari'at adalah batal, dan shari' at tanpa hakikat tidak ada gunanya. ${ }^{10}$

\section{Sejarah Dan Perkembangan Tarekat}

Tarekat merupakan kelanjutan dari tasawuf yang sudah ada sejak zaman nabi. Istilah tarekat mulai muncul pada abad keempat hijriyah ketika tasawuf yang semula sangat ekskulisf dan di lakukan secara individu berubah menjadi sebuah gerakan kolektif dengan beranggotakan kalangan awam. Kondisi ini tidak begitu saja terjadi, tapi memang karena tuntutan keadaan.. Setidaknya ada dua faktor yang menyebabkan lahirnya gerakan tarekat pada masa itu, yaitu faktor kultural dan struktur. ${ }^{11}$ Dari segi politik, dunia Islam sedang mengalami krisis hebat. Di bagian barat dunia Islam, seperti : wilayah Palestina, Syiria, dan Mesir menghadapi serangan orangorang Kristen Eropa, yang terkenal dengan Perang Salib. Selama lebih

8 Sayyid Bakri Bin Shata. Kifayatul Atqiya Waminhajil Asfiya.( Misr : Alhairiyyah), 9 .

\section{${ }^{9}$ Ibid, 13 .}

${ }^{10}$ Ibid, 8 .

11 Ahmad Tafsir, "Tarekat dan Hubungannya dengan Tasawuf", dalam Harun Nasution (ed.), Thoriqot Qadiriyah Naqsyabandiyah : Sejarah, Asal-usul dan Perkembangannya,( Tasikmalaya: IAIIM, 1990, ) h. 28 
kurang dua abad (490-656 H. / 1096-1258 M.) telah terjadi delapan kali peperangan yang dahsyat ${ }^{12}$. Di bagian timur, dunia Islam menghadapi serangan Mongol yang haus darah dan kekuasan. Ia melahap setiap wilayah yang dijarahnya. Demikian juga halnya di Baghdad, sebagai pusat kekuasaan dan peradaban Islam. Situasi politik kota Baghdad tidak menentu, karena selalu terjadi perebutan kekuasan di antara para Amir (Turki dan Dinasti Buwihi) $^{13}$.

Kerunyaman politik dan krisis kekuasaan ini membawa dampak negatif bagi kehidupan umat Islam di wilayah tersebut. Pada masa itu umat Islam mengalami masa disintegrasi sosial yang sangat parah, pertentangan antar golongan banyak terjadi, seperti antara golongan sunni dengan syi'ah, dan golongan Turki dengan golongan Arab dan Persia. Selain itu ditambah lagi oleh suasana banjir yang melanda sungai Dajlah yang mengakibatkan separuh dari tanah Iraq menjadi rusak. Akibatnya, kehidupan sosial merosot. Keamanan terganggu dan kehancuran umat Islam terasa di manamana. $^{14}$

Dalam situasi seperti itu wajarlah kalau umat Islam berusaha mempertahankan agamanya dengan berpegang pada doktrinnya yang dapat menentramkan jiwa, dan menjalin hubungan yang damai dengan sesama muslim.

Masyarakat Islam memiliki warisan kultural dari ulama sebelumnya yang dapat digunakan, sebagai pegangan yaitu doktrin tasawuf, yang merupakan aspek kultural yang ikut membidani lahirnya gerakan tarekat pada masa itu. Dan yang tidak kalah pentingnya adalah kepedulian ulama

${ }^{12}$ K. Ali, A Study of Islamic History,( Delhi : Idarat Adabi. 1990,) h. 273

13 Hasan Ibrahim Hasan, Islamic History and Culture From 632 - 1968 M, diterjemahkan oleh Djahdan Human (ed) dengan judul : Sejarah dan Kebudayaan Islam , (Yogyakarta : Kota Kembang, 1989,) h. 245 - 266.

${ }^{14}$ K. Ali, op. cit, h. 134-135. 
sufi, mereka memberikan pengayoman masyarakat Islam yang sedang mengalami krisis moral yang sangat hebat (ibarat anak ayam kehilangan induk). Dengan dibukanya ajaran tasawuf kepada orang awam, secara praktis lebih berfungsi sebagai psikoterapi yang bersifat massal. Maka kemudian banyak orang awam yang memasuki majelis dzikir dan halaqahnya para sufi, yang lama kelamaan berkembang menjadi suatu kelompok tersendiri (eksklusif) yang disebut dengan tarekat.

Kelompok-kelompok pengikut tarekat yang banyak selanjutnya melakukan perjalanan dan tersebar ke berbagai kawasan. Pos-pos mereka yang ada di berbagai perbatasan wilayah yang biasanya disebut ribat, dan rumah-rumah peristirahatan mereka yang di sebut hanaqah, dan tempat pengucilan diri para pembimbing spiritual yang di sebut zawiyah, merupakan cikal bakal pusat-pusat kehidupan mistik semacam biara sufi. Sejak abad kesebelas, zawiyah dan hanaqah menyediakan tempat peristirahatan bagi para sufi musafir menyebarkan kehidupan saleh yang baru ke seluruh penjuru pinggiran kota dan memainkan peran yang menentukan dalam islamisasi kawasan perbatasan dan kawasan non Arab di Asia tengah dan Afrika.

Pada perkembangan selanjutnya setelah sufi-sufi besar meninggal dunia, para muridnya yang tersebar luar itu bertekad menyebar luaskan ajaran-ajaran shaikh mereka. Maka pada abad keduabelas Masehi, terbentuklah organisasi-organisasi sufi dengan pengikutnya masingmasing ${ }^{15}$

\section{Macam-Macam Tarekat}

Dari sekian banyak tarekat yang perah muncul sejak abad ke-12 (abad ke-6 H) itu antara lain:

${ }^{15}$ Supriana dan M.karman. Materi pendidikan Agama Islam.(Bandung: Rosda,2004), 258. 
1. Tarekat Qadariyah (dihubungkan kepada Shaikh Abdul Qadir AlJailani, yang wafat di Irak pada 1161/561 H), yang mempunyai peganut di Irak, Turki, Turketan, Sudan, Cina, India dan Indonesia.

2. Tarekat Rifa'iyah (dihubungkan kepada Shaikh Ahmad Ar-Rifa'i, yang wafat di Irak pada 1182 M/578 H), yang mempunyaipengikut di Irak dan Mesir.

3. Tarekat Syadziliyah (dihubungkan kepada syeikh Ahmad AsySyadzili, yang wafat di Mesir pada 1258 M/658 H), yang mempuyai pengikut di Mesir, Afrika Utara, Syiria, dan negeri Arab lainnya.

4. Tarekat Maulawiyah (dihubungkan kepada Shaikh Maulana Jalaluddin Rumi, yang wafat di Konya (Turki) pada 1273 m/672 H), yang berpengaruh pada masyarakat Turki.

5. Tarekat Naqsabandiyah (dihubungkan kepada Shaikh Bahauddin Naqsabandi yang wafat di Bukhara pada 1389 M/791 H), yang mempuyai pegikut di Asia Tengah, Turki, India, Cina, dan Indonesia.

6. Tarekat Suhrawardiah (dihubungkan kepada Abu Al-najib Alsuhrawardi(1097-1168M). Tarekat ini kemudian di kembangkan oleh anak saudaranya, Shihab al-din Abu Hash al-baghdadi ia menyusun kitab Awarifu al-ma'arif yang berisi aturan-aturan tarekat. ${ }^{16}$

\section{Komponen Tarekat}

Di dalam sebuah organisasi tarekat terdapat sejumlah komponen yang meliputi : guru, murid, amalan, dan zawiyah.

\section{Guru Tarekat}

Dalam sebuah tarekat seorang guru tarekat atau biasa disebut sheikh atau murshid, memiliki peranan penting dan bahkan mutlak ada dalam sebuah tarekat. Jika para ulama fikih sebagai pewaris nabi SAW

${ }^{16}$ Ibid, 259. 
mengajarkan ilmu lahir maka para murshid tarekat menjadi pewaris nabi dalam mengajarkan penghayatan keagamaan yang bersifat batin. Oleh sebab itu dalam setiap silsilah tarekat, terlihat posisi nabi SAW berada pada puncaknya, setelah Allah SWT dan malaikat jibril.

Seorang murshid memiliki otoritas dan legalitas kesufian termasuk membimbing, mengawasi dan mengajarkan hidup tasawuf, kepada muridmuridnya. Otoritas itu diperoleh setelah ia belajar dan berlatih sekian lama kepada Murshid pendahulunya dan dipandang mampu menjadi seorang murshid tarekat. Adapun legalitasnya diperoleh dari kepercayaan murshid pendahulunya berupa ijazah, yakni semacam pelantikan yang berisi pengesahan seorang murid menjadi seorang Murshid.

Seorang murshid harus menguasai ilmu syari'at dan ilmu hakikat secara mendalam dan lengkap. Pemikiran, perkataan dan perilakuknya harus mencerminkan akhlaq terpuji.

Tugas seorang murshid tarekat tidaklah ringan, apalagi jika jumlah muridnya banyak dan berdomisili di tempat-tempat yang saling berjauhan satu sama lain. Karenanya, dalam membimbing murid-muridnya, seorang murshid dibantu oleh beberapa wakil yang disebut khalifah atau badal. Dalam tradisi tarekat qadiriyah-Naqsabandiyah, para wakil mursyid disebut wakil talkin. Ini dikaitkan dengan salah satu tugas utama murshid dalam tarekat adalah memberikan talkin kepada calon murid yang akan mengikuti latihan kehidupan tarekat.

Muhammad Amin al Kurdi menyebutkan banyak syarat untuk seorang murshid diantaranya :

1. Harus seorang yang alim dalam segala keilmuan yang dibutuhkan oleh para murid. 
2. Harus seorang yang arif terhadap kesempurnaan hati dan adabadabnya, mengetahui segala bahaya Nafs (hati) dan penyakitnya serta mengetahui bagaimana cara menjaganya kesehatannya.

3. Seorang yang lemah lembut, pemurah kepada kaum muslimin, khususnya kepada para muridnya. Apabila melihat para muridnya belum mampu untuk melawan nafsunya dan kebiasaannya yang jelak misalnya, Beliau lapang dada terhadap mereka setelah menasehatinya dan bersikap lemah lembut kepadanya sampai mereka mendapat petunjuk.

4. Selalu menutupi segala yang timbul dari aib yang menimpa para muridnya.

5. Menjaga diri dari harta para muridnya serta tidak tamak terhadap apaapa yang ada ditangan para muridnya.

6. menjalankan apa yang ia perintahkan pada muridnya dan menjauhi apa yang ia larang, sehingga segala perkataannya berbekas pada diri para muridnya.

7. Tidak banyak bergaul dengan para muridnya kecuali sekedar perlu dan selalu mengingatkan hal-hal yang baru dalam hal tarekat dan syari'at sebagai upaya membersihkan jiwa dan agar beribadah kepada Allah dengan ibadah yang benar.

8. Perkataannya bersih dari berbagai kotoran hawa nafsu, senda gurau, dan dari segala yang tidak bermanfaat.

9. Lemah lembut dan seimbang dalam hak dirinya, sehingga kebesaran dan kehebatannya tidak mempengaruhi dirinya.

10. Selalu memberi petunjuk kepada para muridnya dalam hal-hal yang dapat memperbaiki keadaannya. ${ }^{17}$

\section{Murid atau Salik Tarekat}

\footnotetext{
${ }^{17}$ Sayyid Bakri Bin Shata. Kifayatul Atqiya Waminhajil Asfiya.( Misr : Alhairiyyah), $9.524-526$
} 
Untuk menjadi anggota sebuah aliran tarekat, seseorang terlebih dahulu di tanyai kesiapanya untuk menjadi seorang murid. Setelah benarbenar siap, kemudian sang guru memberikan ritual husus sebagai penyucian diri sebelum dibaiat. Setelah itu, pada hari yang sudah di tentukan oleh sang guru, proses baiat pun dilaksanakan. Dalam baiat itu, seorang calon murid harus berjanji di hadapan murshid untuk memenuhi segala persyaratan yang ditentukan. Yaitu diantaranya wajib tunduk kepada ajaran yang diberikan sang murshid dan tidak dibenarkan melakukan pembangkangan sekecil apapun.

\section{Baiat}

Tahap-tahap (maqam dan hal) yang di lalui oleh para murid merupakan suatu perjalanan yang tidak mudah. Pada tahap permulaan seorang yang ingin memasuki dunia tarekat harus melakukan baiat, yaitu sumpah setia kepada apa saja yang di perintahkan oleh guru serta kebsahanya sebagai seorang yang mengamalkan ilmu tarekat. Dalam upacara baiat juga di ajarkan zikir yang harus di lakukan oleh seorang murid dalam sehari semalam. ${ }^{18}$

Dalam rekomendasi tarekat mu'tabarah ke IX di pekalongan, bahkan di anjurkan agar ajaran tarekat di berikan kepada masyarakat luas dan di perkenalkan pada masyarakat sejak masa kanak-kanak. Menurut Habib Lutfi Ali bin Yahya tarekat bisa di ajarkan kepada siapa saja sesuai dengan tingkat pemhaman dan kemampuan pengamalan agamanya. Hal ini menurut beliau, karena di dalam terkat terdapat berbagai makam cara dan

18 M.Muhsin Jamil, Tarekat dan Dinamika Sosial Politik: Tafsir sosial Sufisme Nusantara(Yogyakarta: Pustaka pelajar,2005),64. 
aturan wirid dari yang paling ringan sampai yang paling berat. Setiap orang bebas memilih tarekatnya sesuia dengan kemampuanya. ${ }^{19}$

\section{Ajaran atau Amalan Tarekat}

Ajaran-ajaran dalam tarekat dapat dibedakan menjadi dua; yaitu ajaran khusus dan ajaran umum. Ajaran yang bersifat khusus adalah amalan yang benar-benar harus dilaksanakan pengikut sebuah tarekat, dan tidak boleh diamalkan oleh orang di luar tarekat atau pengikut tarekat lain.

Amalan khusus ini bisa dilaksanakan secara individual maupun secara kolektif .Sedangkan ajaran yang bersifat umum, yaitu amalan-amalan yang ada dan menjadi tradisi dalam tarekat, tetapi amalan ini juga bisa dilakukan oleh masyarakat Islam di luar pengikut tarekat.

Amalan ini bisa dilaksanakan secara individual (fardiyyah) maupun secara kolektif (jama'ah). Namun, untuk membedakan bahwa suatu amalan itu masuk pada ajaran khusus atau ajaran umum, sangatlah sulit karena semua ajaran yang ada pada tarekat bersumber pada Al qur'an dan Hadis. Sesuatu yang dapat membedakan bahwa ajaran ini bersifat khusus atau bersifat umum adalah pada proses bai'at atau talqin. Apabila seseorang telah mengikuti prosesi tersebut pada suatu tarekat, maka ia akan diberikan amalan-amalan yang memiliki ciri-ciri khusus dalam tarekat tersebut, walaupun umat Islam lain yang bukan pengikut suatu tarekat juga mengamalkan ajaran-ajaran tersebut. Misalnya, setiap tarekat mengajarkan istighfar, salawat, dan zikir nafi itsbat, tetapi biasanya memiliki ciri khusus tarekat tertentu. Walaupun umat Islam pada umumnya mengamalkan zikir

19 Ceramah Habib Lutfi Ali bin Yahya dalam seminar tarekat dan tangan modernitas, di STAIN Pekalongan dalam rangka acara muktamar ke-IX Jam 'iyah Ahl Althariqah Al-mu'tabrah Al-nahdliyah tanggal 27 Februari 2000. 
itu, tetapi belum tentu secara khusus mereka telah mengikuti prosesi bai'at kepada seorang mursyid tarekat.

Salah satu amalan utama yang menjadi inti wirid tarekat adalah zikir. Semua kelompok tarekat mengajarkan zikir. Para ulama sepakat bahwa zikir itu adalah menyebut asma Allah SWT dengan ungkapanungkapan yang baik (kalimah thayyibah), yang telah ditentukan oleh ajaran Islam, seperti membaca tasbih, tahmid, takbir dan tahlil. Selain ungkapanungkapan tersebut, membaca al-Qur'an dan doa-doa yag bersumber dari alQur'an termasuk pula dalam pengertian zikir.

Para ahli tarekat telah berhasil mempraktekkan berbagai teknik berzikir secara sistematis. Mereka membagi zikir atas dua bagian, yaitu: zikir yang diucapkan secara lisan (zikr jahr) dan zikir yang diingat dalam kalbu (zikr khafi). Ucapan yang mereka pilih dalam zikir jahr adalah la ilaha illa Allah. Mereka memilih ungkapan tahlil demikian sebagai formulasi zikir karena ungkapan tersebut mengandung suatu pernyataan yang lengkap bagi seorang muslim, yaitu, penegasian tuhan-tuhan selain Allah SWT. Dengan pengucapan tahlil itu dipastikan bahwa seserang adalah muslim. Ini berbeda denagan ucapan tasbih, tahmid dan takbir, yang tidak dapat mengubah setatus seseorang yang bukan muslim menjadi muslim.

Kalimat la ilaha illa Allah disebut juga kaimat tauhid dan kaimat zikir nafi-isbat (penafian dan pengukuhan). Dalam kalimat la ilaha terkandung makna yang menafikan, tidak ada yang patut disembah, tidak ada yang kaya, tidak ada yang kuasa, dan seterusnya; kemudian dikukuhkan dengan kalimat illa Allah yang mengandung pengertian bahwa Allah-lah satu-satunya yang berhak disembah, Yanga Maha Kaya, Yanga Maha Kuasa, dan seterusnya. Tarekat qadiriyah termasuk salah satu tarekat yang mengutamakan pengamalan zikir nafi-isbat ini.

\section{Zawiyyah Tarekat}


Zawiyyah adalah tempat para salik mengamalkan suluk, zikir, dan berbagai wirid tarekat yang lain. Latar belakang munculnya zawiyyah tidak lepas dari kebiasaan kaum sufi dalam mengembara dari satu tempat ketempat yang lain. Mereka berwatak kosmopolitan dalam mencari pembimbing ruhani, tanpa terikat oleh batas-batas teritorial suatu negara. Dari kebiasaan tersebut, terbentuklah pusat-pusat kegiatan kaum sufi diberbagai kawasan dunia Islam. ${ }^{20}$

\section{Tipologi Tarekat}

Setelah tarekat menyebar dalam dunia Islam setiap aliran terkat mempunyai cirri sendiri-sendiri yang sulit di-tipe-kan.Walaupun begitu secara sederhana melihat kemunculanya paling tidak ada dua kecendrungan sufistik awal di lihat dari dua tokoh terkenal yaitu,Abu al-Qasim Jinaid yang di kenal dengan aliran Iraqi Dan Abu yazaid al-Butami yang di kenal dengan aliran khurasan. Setiap aliran tarekat pasti mempunyai silsilah yang bermuara dari kedua tokoh tersebut.Aliran Khurasan penakanan latihan kerohaniahanya lebih condong kepada ghalab (ekstase) dan sukr (mabuk cinta.Sedangkan aliran Iraqi lebih menekankan kepada Sahw (sobriety). ${ }^{21}$

Selain itu tarekat juag dapat di kelompokkan menjadi dua tipe, Mu'tabarah yaitu tarekat yang mempunyai silsilah sampai kepada Nabi dan sesuai dengan al-Qur'an dan sunnah dan ghairu mu'tabarah yaitu tarekat yang menyimpang dari ajaran Islam.

\footnotetext{
${ }^{20}$ referensi agama.blogspot.com/2011/01/tarekat-dan-tipologinya.html?m=1.

${ }^{21} \mathrm{http} / \mathrm{www} \cdot$ referensiagama.com-tarekat-dan-tipologinya.
} 


\section{Kesimpulan}

1. tarekat memiliki dua pegertian. Pertama, tarekat berarti metode pemberian bimbingan spiritual kepada individu dalam mengarahkan kehidupannya menuju kedekatan diri dengan Tuhan. Kedua, tarekat sebagai persaudaraan kaum sufi (sufi brotherhood) yang ditandai dengan adanya lembaga formal, seperti zawiyah, ribath, atau khanaqah.

2. Tarekat mempunyai komponen pokok yaitu guru, murid, dan ajaran atau amalan.

3. Latar belakang munculnya tarekat pada abad ke 3 dan 4 hijriah adalah kekacauan kondisi sosial dan politik umat islam pada saat itu yang di tandai dengan perebutan kekuasaan dan penyerangan tentara mongol.

4. Pada awal kemunculannya tarekat hanya merupakan amalan pribadi sufi besar, akan tetapi pada perkembangannya melembaga karena dalam pengamalannya dilakukan secara berkelompok 


\section{DAFTAR PUSTAKA}

Abdusshomad, Muhyiddin. Hujjah NU Akidah-Amaliah-Tradisi. Surabaya: Khalista,2008

Islam, M. H. (2017). Tolerance in Persepective Of Qur'an And Bibel (Comparative Analysis of Religious Tolerance in Diverses Community). Humanistika, 3(2), 45-58.

Jamil,M.Muhsin Tarekat dan Dinamika Sosial Politik: Tafsir sosial Sufisme Nusantara, Yogyakarta: Pustaka pelajar,2005

K. Ali, A Study of Islamic History, Delhi : Idarat Adabi. 1990

Kurdy (al), Amin. Tanwir Al-qulu $>$ b Fi mu'a $>$ malati Allam Al-ghuyu $<$ b.

Surabaya: Al-hidayah, t.th.

Mahmud, Abdul Halim. Al-mundid min Al-dalal: Dirasat Wa abhas An Tasawuf Misr : Dar Al-kutub Al-misriyah.t.th.

Mustofa, A. Akhlak Tasawuf. Bandung: Pustaka Setia.1999

Islam, M. H. (2019, November). Model Pendekatan Halaqotul MuAllimin Al-Islamiyah dalam Membentuk Kepribadian Yang Rahmatan Lil Alamin Sebagai Identitas Kebangsaan di Pondok Pesantren AlMashduqiah. In Proceedings of Annual Conference for Muslim Scholars (Vol. 3, No. 1, pp. 491-503).

Islam, M. H. (2020). TOLERANCE LIMITATION IN FACING RELIGIOUS DIVERSITY BASED ON THE TEACHING OF ISLAM. Nazhruna: Jurnal Pendidikan Islam, 3(1), 1-13.

Nasution, Harun. Thoriqot Qadiriyah Naqsyabandiyah : Sejarah, Asal-usul dan Perkembangannya, Tasikmalaya: IAIIM, 1990

Supriana dan M.karman. Materi pendidikan Agama Islam.Bandung: Rosda,2004 